\title{
Midazolam infusion and disease severity affect the level of sedation in children: a parametric time-to-event analysis of data from the 'daily sedation interruption in critically ill children' trial
}

Parth Upadhyay ${ }^{1}$, Nienke Vet ${ }^{2}$, Sebastiaan Goulooze ${ }^{1}$, Elke Krekels ${ }^{1}$, Saskia De wildt ${ }^{3}$, and Catherijne Knibbe ${ }^{1}$

${ }^{1}$ Leiden University Faculty of Science

${ }^{2}$ Sint Antonius Ziekenhuis

${ }^{3}$ Radboud University Medical Center

January 4, 2021

\begin{abstract}
Aim In critically ill mechanically ventilated children, midazolam is used first line for sedation, however its sedative effects have been difficult to quantify for which novel quantification methods are still required. In this analysis, we use parametric time-toevent (PTTE) analysis to quantify the effects of midazolam in critically ill children. Methods For the PTTE analysis, data was analyzed from a published sedation interruption study in mechanically ventilated critically ill children. In this study, blinded midazolam or placebo infusions were administered during the sedation interruption phase until, based on COMFORT-B and NISS scores, patients became undersedated and unblinded midazolam was restarted. Using NONMEM@ v.7.4.3.,the restart of unblinded midazolam was analysed as a clinical event, followed by internal and external validation. Results Data contained 138 events from 79 individuals ( 37 blinded midazolam; 42 blinded placebo). In the PTTE model, a constant function best described the baseline hazard. The use of midazolam reduced the hazard for restart of unblinded midazolam due to undersedation by $51 \%$. In the blinded midazolam group, time to midazolam restart was $26 \mathrm{~h}$ versus $58 \mathrm{~h}$ in patients with low versus high disease severity upon admission (PRISM II <10 versus $>21$ ), respectively. For blinded placebo these times were $14 \mathrm{~h}$ and $33 \mathrm{~h}$, respectively. The model performed well in an external validation with 42 individuals. Conclusion The PTTE analysis effectively quantified the effect of midazolam and the influence of disease severity on sedation in mechanically ventilated critically ill children and provides a valuable tool to quantify sedative efficacy
\end{abstract}

\section{Hosted file}

Parth-PTTEmidazolam DSI-03122020-manuscript.pdf available at https://authorea.com/users/ 387108/articles/502405-midazolam-infusion-and-disease-severity-affect-the-level-ofsedation-in-children-a-parametric-time-to-event-analysis-of-data-from-the-dailysedation-interruption-in-critically-ill-children-trial

\section{Hosted file}

Parth-PTTEmidazolam DSI-03122020-Table1.pdf available at https://authorea.com/users/387108/ articles/502405-midazolam-infusion-and-disease-severity-affect-the-level-of-sedationin-children-a-parametric-time-to-event-analysis-of-data-from-the-daily-sedationinterruption-in-critically-ill-children-trial

\section{Hosted file}


Parth-PTTEmidazolam DSI-03122020-Table2.pdf available at https://authorea.com/users/387108/ articles/502405-midazolam-infusion-and-disease-severity-affect-the-level-of-sedationin-children-a-parametric-time-to-event-analysis-of-data-from-the-daily-sedationinterruption-in-critically-ill-children-trial
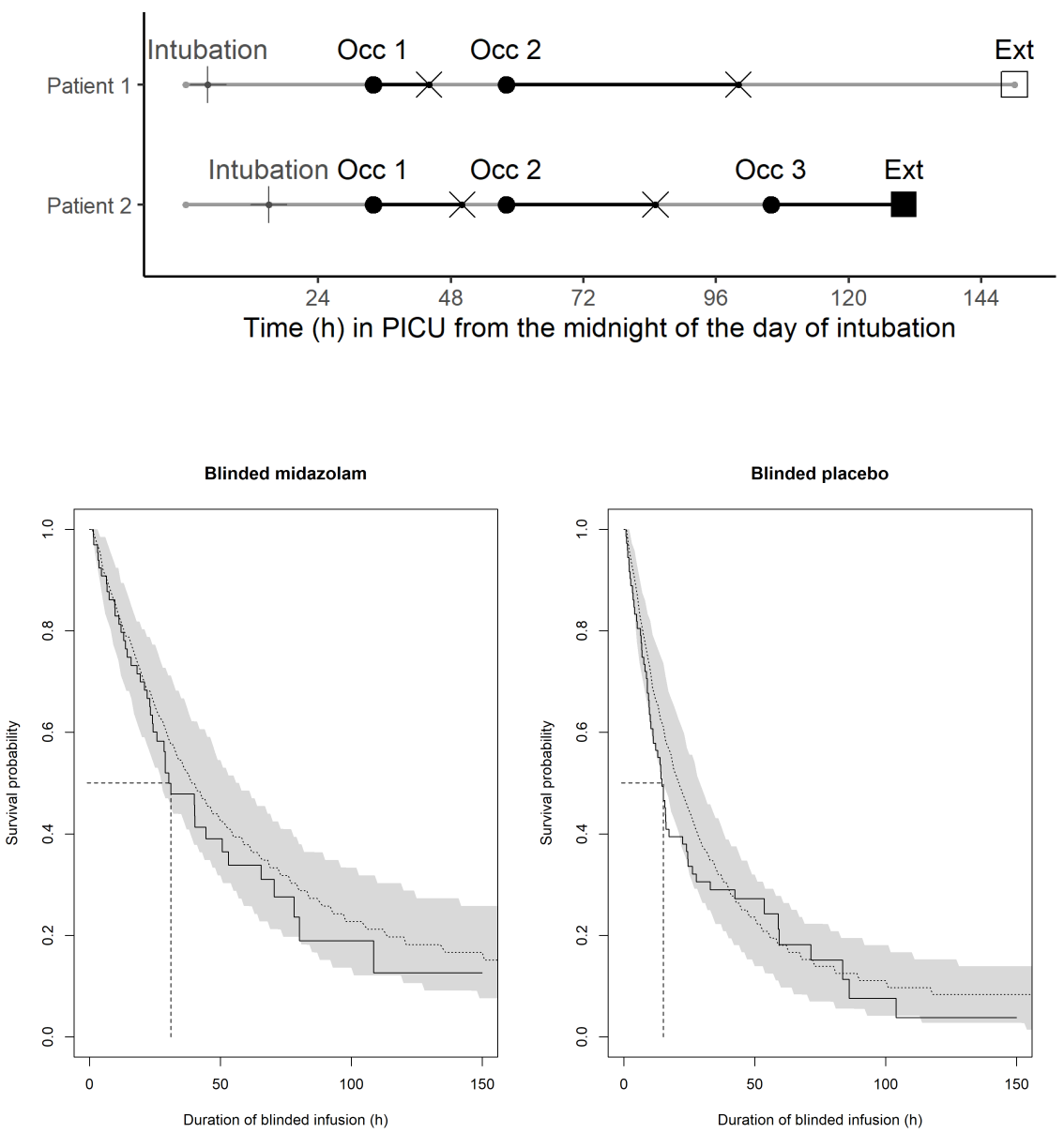


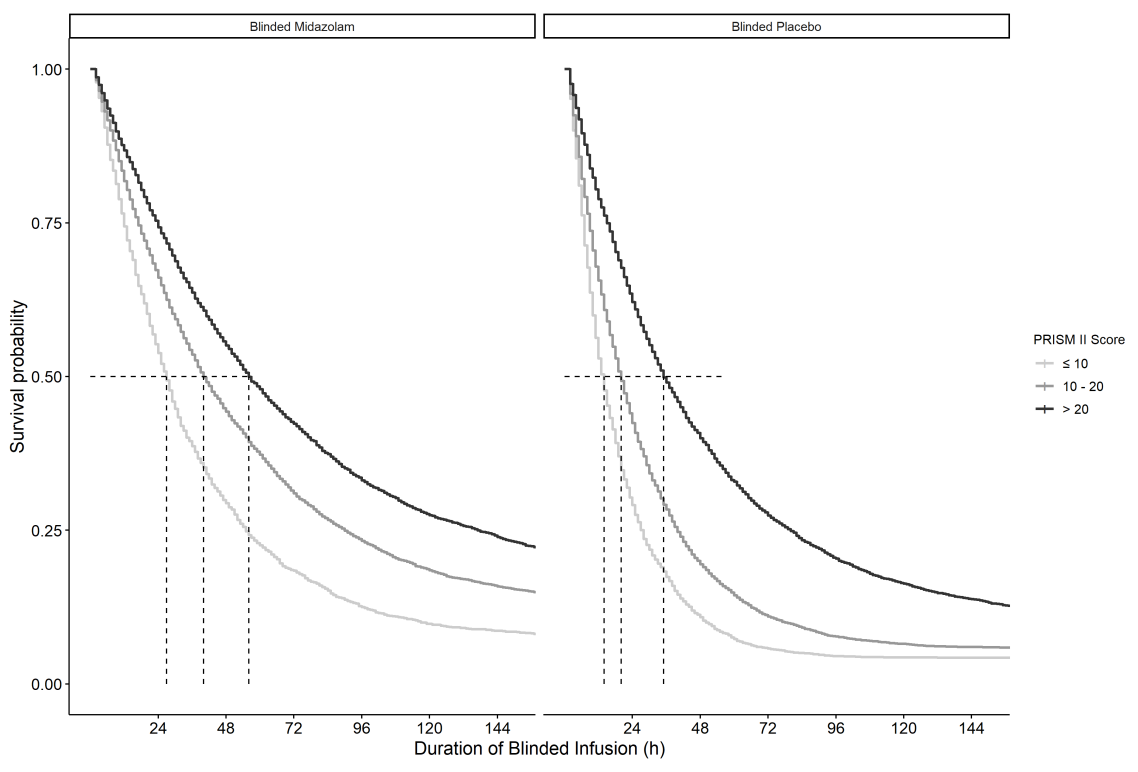

